\title{
Cost and detection rate of glaucoma screening with imaging devices in a primary care center
}

\author{
This article was published in the following Dove Press journal: \\ Clinical Ophthalmology \\ 16 February 2017 \\ Number of times this article has been viewed
}

\author{
Alfonso Anton ${ }^{1-4}$ \\ Monica Fallon ${ }^{3,5}$ \\ Francesc Cots ${ }^{2}$ \\ María A Sebastian ${ }^{6}$ \\ Antonio Morilla-Grasa ${ }^{4}$ \\ Sergi Mojal ${ }^{3}$ \\ Xavier Castells ${ }^{2}$ \\ 'Medicine School, Universidad \\ Internacional de Cataluña, ${ }^{2}$ Servei \\ d'Estudies, Parc de Salut Mar, \\ ${ }^{3}$ Instituto Hospital del Mar de \\ Investigaciones Médicas (IMIM), \\ ${ }^{4}$ Glaucoma Department, Instituto \\ Catalán de Retina (ICR), ${ }^{5}$ Universidad \\ Autónoma de Barcelona, ${ }^{6}$ Centro \\ de Atención Primaria Larrard, \\ Barcelona, Spain
}

Purpose: To analyze the cost and detection rate of a screening program for detecting glaucoma with imaging devices.

Materials and methods: In this cross-sectional study, a glaucoma screening program was applied in a population-based sample randomly selected from a population of 23,527. Screening targeted the population at risk of glaucoma. Examinations included optic disk tomography (Heidelberg retina tomograph [HRT]), nerve fiber analysis, and tonometry. Subjects who met at least 2 of 3 endpoints (HRT outside normal limits, nerve fiber index $\geq 30$, or tonometry $\geq 21$ $\mathrm{mmHg}$ ) were referred for glaucoma consultation. The currently established ("conventional") detection method was evaluated by recording data from primary care and ophthalmic consultations in the same population. The direct costs of screening and conventional detection were calculated by adding the unit costs generated during the diagnostic process. The detection rate of new glaucoma cases was assessed.

Results: The screening program evaluated 414 subjects; 32 cases were referred for glaucoma consultation, 7 had glaucoma, and 10 had probable glaucoma. The current detection method assessed 677 glaucoma suspects in the population, of whom 29 were diagnosed with glaucoma or probable glaucoma. Glaucoma screening and the conventional detection method had detection rates of $4.1 \%$ and $3.1 \%$, respectively, and the cost per case detected was 1,410 and $1,435 €$, respectively. The cost of screening 1 million inhabitants would be 5.1 million euros and would allow the detection of 4,715 new cases.

Conclusion: The proposed screening method directed at population at risk allows a detection rate of $4.1 \%$ and a cost of 1,410 per case detected.

Keywords: screening, glaucoma, cost, imaging devices, detection rate

\section{Introduction}

Glaucoma meets some of the criteria recommended by the World Health Organization in order to consider screening programs useful and cost-effective. It has been estimated that $67 \%$ of affected individuals are undetected in the $\mathrm{UK}^{1}$ and $71 \%$ in Spain. ${ }^{2}$ However, selective screening of groups with a higher disease prevalence based on age, African ethnicity, and family history could be worthwhile. Burr et al predicted that screening could be cost-effective in a 50 -year-old cohort at a prevalence of $4 \%$ with at least a 2 -year screening interval. ${ }^{1}$

Similarly, the question of which tests should be used to screen for glaucoma has no definite, scientifically proven, or even a consensus answer. ${ }^{3}$ Intraocular pressure is usually included in screening protocols associated with other tests to identify the most important risk factor, even though it has little value as a diagnostic test for glaucoma. Short functional tests of different kinds have proved useful for glaucoma screening, but they all have relevant disadvantages including a relatively long testing
Universidad Internacional de Cataluña, Glaucoma Consultant, Parc de Salut Mar, Glaucoma and Research Departments, Instituto Catalán de Retina, Pau Alcover 67, Barcelona 08017, Spain Tel +34932540565 ext 300/302 Fax +34932540567 Email aanton@uic.es 
time (one to several minutes) and the learning effect. These are particularly important for screening programs targeting a perimetrically inexperienced population. All functional tests require the subjects' active participation and repeated examinations ${ }^{4}$ to overcome the learning effect. They frequently show high false-positive classification rates. ${ }^{3-6}$ For these reasons no functional test was used in this study.

An option increasingly used for screening is the acquisition of optic nerve and/or retinal nerve fiber layer photographs or images. Photographs are easily obtained with non-mydriatic cameras in seconds in most subjects. Even easier is the acquisition of images with scanning laser ophthalmoscopy (Heidelberg retina tomograph [HRT]), scanning laser polarimetry (Nerve fiber analyzer [GDx]), or optical coherence tomography (OCT), and there are many reports indicating their usefulness for glaucoma diagnosis. ${ }^{3,7-9}$ Photographs require subjective physician evaluation, whereas imaging devices allow automatic classification of cases and results can be sent anywhere as a small pdf file. Physician supervision may be reduced to quality control and confirmation of abnormal imaging results, which may significantly decrease assessment time and cost. De Mul et al showed that GDx images obtained and filtered by optometrists are useful for glaucoma screening by telemedicine, ${ }^{10}$ while Blazquez et al, ${ }^{11}$ Ohkubo et al, ${ }^{8}$ and Toth et $\mathrm{al}^{9}$ reported the usefulness of HRT for glaucoma screening.

Finally, the literature on costs and effectiveness of screening for glaucoma, particularly with imaging devices, is limited. A systematic review of cost-effectiveness of screening strategies for open-angle glaucoma (OAG) reported the absence of sufficient economic evidence for determining if screening for OAG should be performed and, if it should, then how should it be performed. ${ }^{12}$

The goal of the current study was to analyze the cost and the detection rate of a screening program for detecting glaucoma based on imaging devices.

\section{Materials and methods Design}

This was a cross-sectional population-based study. Costs and detection rate of a screening program and also those of current conventional detection used by the Sistema Nacional de Salud (the Spanish National Health System, NHS) were assessed in the same population but in different specific samples. Only cases newly diagnosed by one of the 2 detection methods were considered for all calculations.

\section{Study population and samples}

The study population comprised 23,527 subjects $>40$ years of age included in the census of the primary care center (PCC)
CAP Larrard (Barcelona, Spain). The sample to evaluate glaucoma screening comprised 1,600 subjects randomly selected from this population. This number was estimated as sufficient to reach the 343 subjects required according to sample size calculation (see below), taking into consideration that health registers are sometimes incomplete or outdated, and an expected $50 \%$ participation rate. Of those 1,600, 1 subject was duplicated and 36 were deceased, so the initial study sample included 1,563 subjects. To assess conventional detection, the sample comprised all patients visiting primary care physicians for any ophthalmic reason and/or attending ophthalmic consultation at the PCCs (a general ophthalmologist sees patients at the PCC) during the study period. These data were obtained from the electronic medical records of all 23,527 subjects in the population.

\section{Sample size calculation}

Sample size was calculated from prevalence rates of glaucoma and ocular hypertension $(\mathrm{OH})$ of $2.1 \%$ and $1.6 \%,{ }^{2}$ respectively, and an estimated rate of undiagnosed cases of $70 \%$. Assuming an alpha risk of 0.05 , an accuracy of $\pm 0.02 \%$, and for an estimated proportion of 0.037 (this figure comes from adding prevalence of glaucoma [0.021] and $\mathrm{OH}$ [0.016] in Spain), a sample of at least 343 subjects evaluated by each detection method was required to identify differences in the cost and the detection rate between conventional detection and the screening program.

\section{Glaucoma screening}

\section{Contact with participants}

The screening program was advertised at the PCC and all subjects received a phone call during which the study was explained, the presence or absence of glaucoma risk factors was initially evaluated with a brief questionnaire, initial oral consent was requested, and a visit was scheduled. In cases of doubt concerning inclusion criteria, the subject was also scheduled for examination. A minimum of 3 calls at different times of the day were made before subjects were considered unreachable.

\section{Subjects}

The screening program targeted subjects at risk for glaucoma with one of the following conditions: age $>60$ years or $>40$ years with at least one other risk factor (personal history of $\mathrm{OH}$, family history of glaucoma, myopia exceeding 3 diopters, or African ethnicity).

\section{Examinations}

Subjects who met the inclusion criteria were evaluated at the PCC after giving their written informed consent. One 
optometrist and 4 ophthalmic nurses experienced in image acquisition were specifically trained for this study (20 hours of training sessions). They measured visual acuity, administered a health questionnaire, confirmed inclusion criteria, acquired HRT-3 images (Heidelberg Engineering, Heidelberg, Germany), GDx-VCC images (Carl Zeiss Meditec, Dublin, CA, USA), and performed rebound tonometry (Icare, Icare Finland Oy, Espoo, Finland).

\section{Data analysis}

Only good quality images were considered and used to classify subjects. The HRT-III images had to be of "fair" or better quality (good, very good, or excellent), with topographic standard deviation $<40 \mu$, centered, and sharp. Images were considered abnormal if the global Moorfields regression analysis (MRA) was borderline or outside the normal limits. GDx-VCC images had a quality index Q of 6 or better and were centered and sharp. Images were considered outside the normal limits if the nerve fiber index (NFI) was $\geq 30$.

\section{Definitions and classification}

Screening was considered positive if at least 2 of the following criteria were met in at least 1 eye: intraocular pressure (IOP) $>21 \mathrm{mmHg}$, HRT outside the normal limits, and/or GDx-VCC outside the normal limits. The screening result was considered negative in all other cases or combination of results (Figure 1). Nevertheless, when both images were normal and the IOP was $>21 \mathrm{mmHg}$, the patient was classified as ocular hypertensive and was not scheduled for

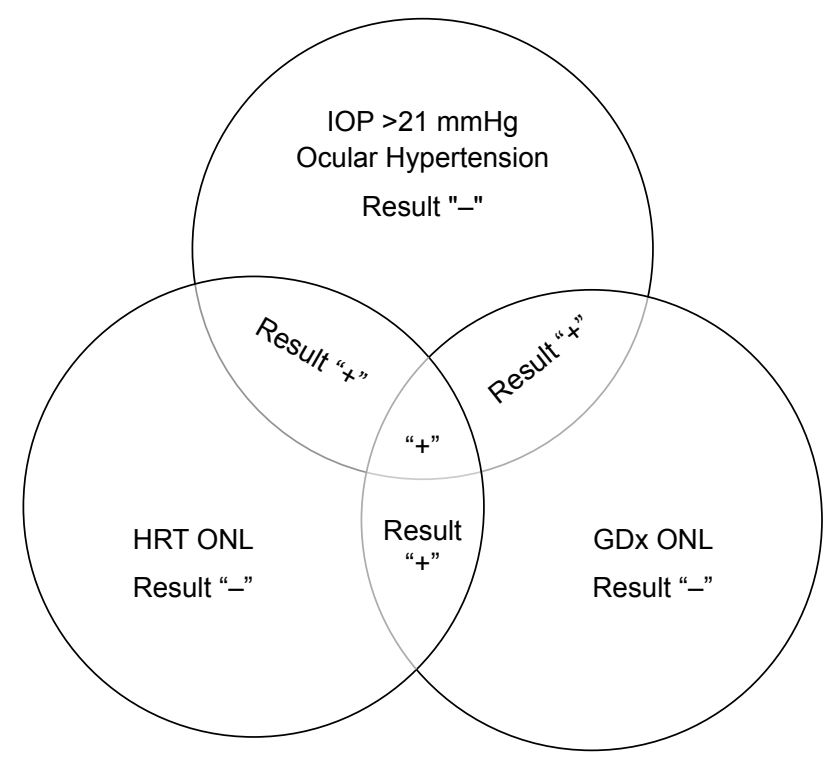

Figure I Definition of positive and negative results at screening.

Note: A positive result was defined as the presence of at least 2 tests outside normal limits.

Abbreviations: IOP, intraocular pressure; HRT, Heidelberg retina tomograph; ONLs, outside normal limits. glaucoma consultation within the study protocol but was recommended repeated ophthalmic visits at the PCC. The protocol specified that IOP values $>30 \mathrm{mmHg}$ should be sent within 24 hours for ophthalmic consultation at the hospital, but no such cases were found. Images were initially evaluated by nurses and optometrists at the PCC, captured by a telemedicine application and sent to the referral hospital where a glaucoma specialist reviewed all positive cases and $10 \%$ of negative cases. The latter was performed as a quality check. Subjects classified as positive were referred to glaucoma consultation. Subjects classified as negative at screening but having high IOP were classified as $\mathrm{OH}$. Together with those identified by nurses/optometrists as suspected of having some other eye disease, they were advised to schedule an ophthalmic consultation.

\section{Conventional detection}

Current glaucoma detection within the Spanish NHS occurs via primary care doctors, optometrists, and ophthalmologists when a patient decides to visit them. In order to estimate the cost and the detection rate of this "conventional detection" process, data were included from the electronic medical records of all subjects $>40$ years of age referred to the ophthalmologists at the PCC for glaucoma, suspected glaucoma, $\mathrm{OH}$, or a positive family history of glaucoma, together with those who were diagnosed with any of these pathologies. This took place the year before the screening campaign was performed, in order to avoid the positive influence of advertisements and brochures about glaucoma on conventional detection. A total of 932 subjects initially met the criteria, of whom 255 were not evaluated by a primary care physician and not referred for ophthalmic consultation for different reasons (already diagnosed and followed up elsewhere or risk factors not confirmed). Age, gender, ophthalmic history, reason for referral, and results of the ophthalmic visits at the PCC and the hospital were recorded and analyzed. Patients detected during the study underwent glaucoma consultation at the hospital (Figure 2).

\section{Glaucoma consultation}

The goal of the glaucoma consultation was to confirm or rule out the diagnosis of glaucoma with the following tests: refraction, Goldman tonometry, Humphrey 24-2 Swedish interactive threshold algorithm (SITA) standard fields, gonioscopy, optic disc photography, and an examination of the anterior and posterior segments performed by an experienced glaucoma expert (Alfonso Anton, AA). The examinations were performed at the referral hospital. HRT and GDx images acquired at screening were also available for the glaucoma 


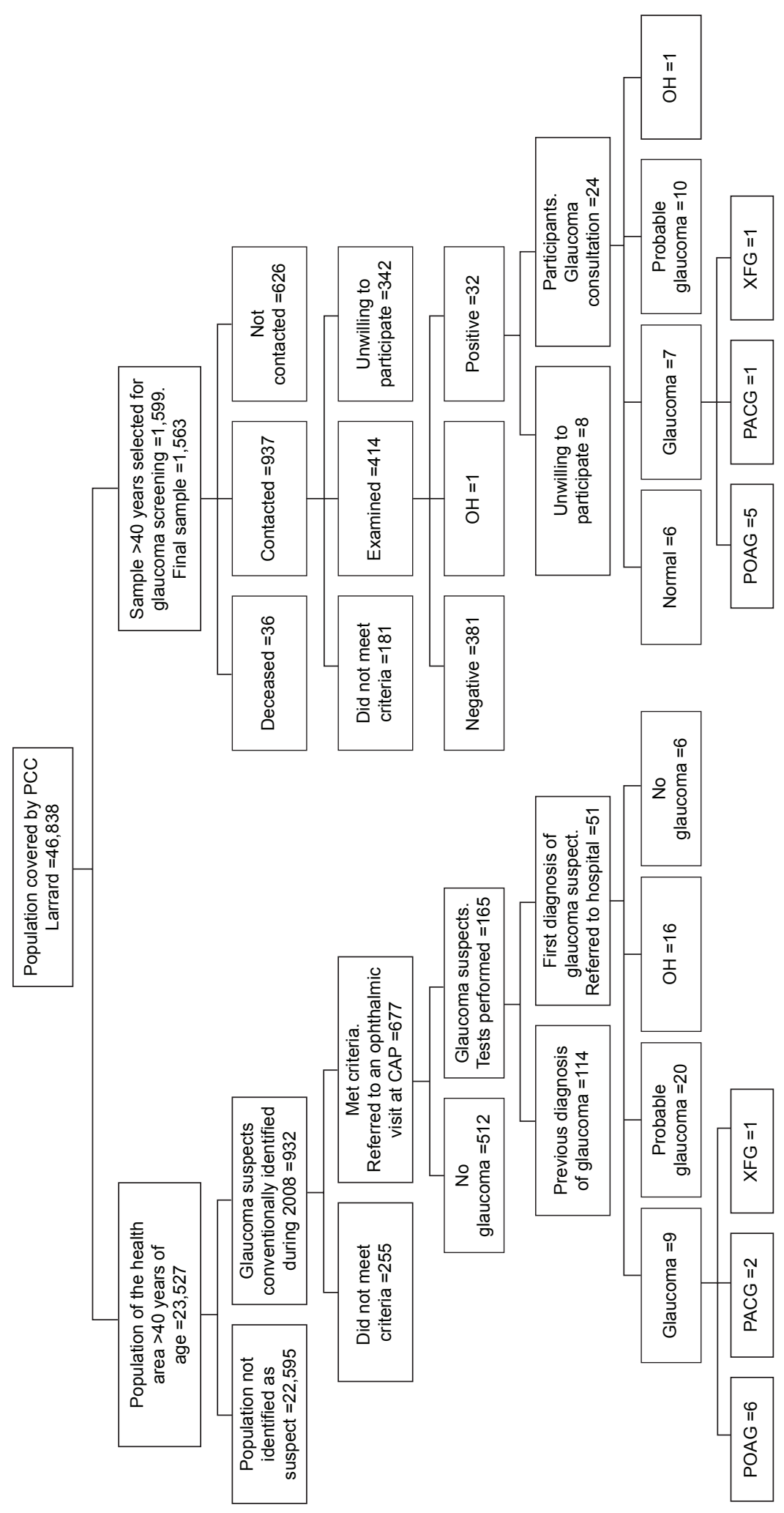

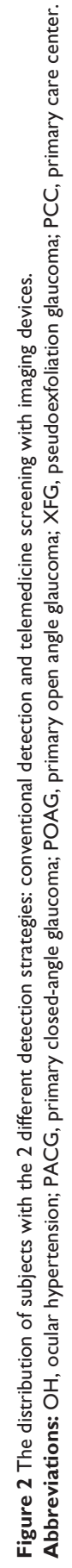


consultant. Patients were classified as normal or with $\mathrm{OH}$, probable glaucoma, or glaucoma according to the criteria shown in Table 1. The degree of glaucoma at diagnosis was established according to the mean deviation in the worse eye. Patients were classified as having early, moderate, or advanced glaucoma if the mean deviation (Humphrey SITA standard fields) was between 0 and $-6 \mathrm{~dB}$, ranged from -6 to $-15 \mathrm{~dB}$, or was $<-15 \mathrm{~dB}$, respectively.

\section{Detection rate}

The detection rate was calculated by dividing the number of new cases identified during the study by the total number of cases examined.

\section{Cost assessment and sensitivity analysis}

The cost was calculated by adding the unit costs of all resources used in the different activities occurring during the diagnostic process. This process included all activities and procedures performed to detect cases with glaucoma from the first visit or the invitation to participate in the screening campaign to the moment when the ophthalmologist established the diagnosis. The criteria used were based on the concept of activity-based costing. This method was specifically applied for this study at the PCC, while in the Hospital we used a standardized cost-accounting system. ${ }^{13,14}$ Costs included health professionals, devices, and infrastructure at the PCC and the hospital. Personnel costs were calculated from the total cost of each professional participating in a certain activity according to the time specifically dedicated to that particular activity. For example, nurses or optometrists who performed the screening dedicated 12 of 35 hours of their weekly work time to the diagnostic process and only that part of their full salary was considered a cost. For doctors, who performed different tasks (training, examination, or test interpretation), only the cost of the fraction of their work time dedicated to the specific task involved in the glaucoma diagnostic process

Table I Classification criteria

\begin{tabular}{llll}
\hline Diagnosis & IOP $(\mathbf{m m H g})$ & Optic disc & Visual field \\
\hline Normal & $<22$ & Normal & Normal \\
OH & $\geq 22$ & Normal & Normal \\
Probable glaucoma & Any & Glaucomatous & Normal \\
& Any & Normal & Glaucomatous $^{\mathrm{a}}$ \\
Glaucoma & Any & Glaucomatous $^{\mathrm{b}}$ & Glaucomatous $^{\mathrm{a}}$ \\
\hline
\end{tabular}

Notes: a Glaucomatous field: 3 contiguous locations outside normal limits in the pattern deviation plot. 'Glaucomatous optic disc: presence of rim thinning, and/ or cup/disk asymmetry of $>0.3$ and/or disk hemorrhage and/or nerve fiber layer defect. Based on direct examination at the slit lamp, disk photographs, HRT, and GDx images.

Abbreviations: GDx, nerve fiber analyzer; HRT, Heidelberg retina tomograph; $\mathrm{IOP}$, intraocular pressure; $\mathrm{OH}$, ocular hypertension. was added. The costs of the devices and materials (GDxVCC, HRT, tonometer, ophthalmoscope, retinograph, and lenses) were calculated based on a 5-year amortization and the total number of tests performed annually. The costs of disposable materials used in the ophthalmic visits (eye drops and tissues) were also added. The fixed (or structural) costs at the PCC (electricity, water, gas, maintenance, and security) were estimated from the global structural costs of the facility divided by the total number of patients seen and multiplied by the number of patients evaluated in the detection process. The structural costs at the hospital (glaucoma consultation) were taken from the hospital cost-accounting system, ${ }^{13,14}$ which calculates structural costs for each department related to the consumption of resources. The fixed costs computed for the Department of Ophthalmology comprise an additional 20\% of the cost of each activity.

Costs calculated for the screening program were based on its application to the study sample. As costs may vary significantly depending on the size of the target population and other factors, a sensitivity analysis was performed. First, costs were also calculated considering a mean of the detection rate calculated by other studies $(4.9 \%)^{8,9,27}$ using the same imaging devices. Second, the costs of screening in the population were recalculated through the activity that would be generated by the implementation of the screening program studied in the NHS in a community of 1 million subjects. This calculation was performed using the participation and detection rates obtained in this study and assuming that 1 nurse, 1 optometrist, and 1 assistant could perform the telemedicine screening program at the PPC. This framework proved both feasible and effective for this study. Finally, the cost per case detected was calculated by dividing the total cost of all cases detected by the number of cases detected by each detection method.

\section{Ethics}

The study was approved by the Research Commission and the Ethics Committee of the Parc de Salut Mar. The study complied with the tenets of the Declaration of Helsinki.

\section{Results}

Of the sample selected $(n=1,563)$ for glaucoma screening, $626(40 \%)$ subjects could not be reached, $181(12 \%)$ were located but did not meet the risk criteria, and 756 (48\%) met the risk criteria. Of the latter, 342 (45\%) did not want to participate and in 19 , the reason was that they already had been diagnosed with glaucoma. The participation rate among those reached and meeting the criteria was 
55\% (414/756; Figure 2). Demographic characteristics are shown in Table 2. A total of 932 subjects from the same population underwent conventional evaluation the year before the screening was performed.

\section{Glaucoma screening}

Of the 414 subjects who completed the screening program, 13 subjects $(3.1 \%)$ had an IOP $>21 \mathrm{mmHg}$ in at least 1 eye and in 7 of them the pressure was high bilaterally. The mean IOP \pm standard deviation was $14.5 \pm 3.7 \mathrm{mmHg}$ (range, 7-30). Good-quality HRT images could not be obtained in 53 eyes (6.4\%), the MRA was normal in 602 eyes (72.7\%), and outside the normal limits or borderline in 173 eyes $(20.3 \%)$. Obtaining good-quality GDx images was unfeasible in 69 eyes $(8.3 \%)$, while the NFI was normal in 666 eyes $(80.5 \%)$ and abnormal in 93 eyes $(11.2 \%)$. Thirty-two subjects $(7.7 \%)$ were classified as positive at screening (Figure 2).

Additionally, glaucoma screening identified 31 subjects with other ophthalmic pathologies different from glaucoma, 7 tested negative in glaucoma screening but were also referred for ophthalmic consultation. The other 24 resulted positive during the screening process. Pathologies identified included 15 cataracts, 6 myopias, 2 age-related macular degenerations, and only 1 case of several diseases (blepharitis, retinal toxoplasma scars, retinal detachment, scleromalacia, ptosis, band queratopathy, non-proliferative diabetic retinopathy, and lens subluxation).

\section{Conventional detection}

Figure 2 shows the distribution of all subjects evaluated $(n=932)$ for glaucoma at the PCC or who were suspected of having the disease. Of the 932 individuals evaluated by the primary care doctor, 255 were evaluated only by the primary care physician, 677 were referred to a general ophthalmologist at the PCC, and 51 were newly diagnosed with glaucoma or suspected glaucoma and required ophthalmic testing (Figure 2). The conventional detection method also identified 41 cases with other pathologies including 26 blepharitis, 5 cataracts, 2 cases with pathologic myopia, 2 with non-proliferative diabetic retinopathy, 2 with age-related macular degeneration, and 1 case of several pathologies (floppy eyelid, cornea guttata, pterigion, vascular sclerosis, and retinoschisis).

\section{Glaucoma consultation}

The 32 subjects who were positive at the screening program were invited to attend a glaucoma consultation. Eight did not want to continue the study (6 were seeing another glaucoma specialist and 2 did not specify a reason) and 24 completed the glaucoma visit. Six were normal, 7 were diagnosed with glaucoma, 10 were classified as having probable glaucoma, and 1 had $\mathrm{OH}$. Five of the 7 glaucoma cases were primary OAG, 1 had primary angle-closure glaucoma, and 2 pseudoexfoliation glaucoma. The latter was also the only patient in the sample who had high IOP and both images (HRT and GDx) outside the normal limits (Figure 1).

Of the 51 subjects identified by the conventional examination in the population, 6 were normal, 16 had $\mathrm{OH}, 20$ had probable glaucoma, and 9 were diagnosed with definite glaucoma (6 primary OAG, 2 primary angle-closure glaucoma, and 1 pseudoexfoliation glaucoma).

Table 2 Demographics of the participants

\begin{tabular}{|c|c|c|c|c|}
\hline Variable & Population & $\begin{array}{l}\text { Randomly selected } \\
\text { screening sample }\end{array}$ & $\begin{array}{l}\text { Subjects included and } \\
\text { examined at screening } \\
\text { program (randomly } \\
\text { selected and invited } \\
\text { to participate) }\end{array}$ & $\begin{array}{l}\text { Subjects examined by } \\
\text { current detection method } \\
\text { (belong to same population } \\
\text { but entered the detection } \\
\text { process spontaneously with } \\
\text { no prior selection) }\end{array}$ \\
\hline Subjects $>40$ years & 23,527 & 1,599 & 414 & 165 \\
\hline Age (years) mean \pm SD (range) & $63.37 \pm 10.61(40-100)$ & $63.29 \pm 14.73(40-100)$ & $65.2 \pm 11(40-93)$ & $70.2 \pm 9.8(43-94)$ \\
\hline $40-49(\%)$ & $5,256(22.3)$ & $358(22.4)$ & $50(12.0)$ & $8(4.8)$ \\
\hline $50-59(\%)$ & $4,947(21.0)$ & $336(21.0)$ & $69(16.7)$ & $12(7.3)$ \\
\hline 60-69 (\%) & $4,886(20.8)$ & $332(20.7)$ & $135(32.6)$ & $52(31.5)$ \\
\hline 70-79 (\%) & $4,36 \mid(18.5)$ & $297(18.5)$ & $107(25.9)$ & $64(38.8)$ \\
\hline 80-89 (\%) & $3,226(13.7)$ & $219(13.6)$ & $52(12.6)$ & $28(17.0)$ \\
\hline 90-99 (\%) & $851(3.6)$ & $58(3.6)$ & I $(0.2)$ & I $(0.6)$ \\
\hline \multicolumn{5}{|l|}{ Gender (\%) } \\
\hline Women & $14,155(60.2)$ & $986(6 \mid .6)$ & $249(60.1)$ & $106(64.2)$ \\
\hline Men & $9,372(39.8)$ & $613(38.3)$ & $165(39.9)$ & $59(35.8)$ \\
\hline
\end{tabular}

Abbreviation: SD, standard deviation. 
Table 3 Degree of glaucoma in detected cases

\begin{tabular}{lll}
\hline Variable & $\begin{array}{l}\text { Screening } \\
\text { program }\end{array}$ & $\begin{array}{l}\text { Conventional } \\
\text { detection }\end{array}$ \\
\hline Mean deviation (range) & $-3.54 \pm 2.63$ & $-5.52 \pm 7.18$ \\
& $(-10.31$ to -0.14$)$ & $(-25$ to 0$)$ \\
Visual field index (range) & $97.85 \pm 2.20$ & $81.92 \pm 21.32$ \\
& $(94$ to 100$)$ & $(25$ to 100$)$ \\
Degree of glaucoma according to mean defect $(\mathrm{dB})$ & \\
Initial, 0 to -6 & $15(88.23 \%)$ & $14(56 \%)$ \\
Moderate, -6.1 to -15 & $2(11.77 \%)$ & $5(20 \%)$ \\
Advanced, $<-15.1$ & - & $6(24 \%)$ \\
\hline
\end{tabular}

The detection rates of cases with glaucoma or probable glaucoma (both considered new cases) were 3.1\% and $4.1 \%$, respectively, for conventional detection and glaucoma screening with imaging devices. Table 3 shows the severity of glaucoma in the cases diagnosed using both detection methods. The visual field parameters of the cases identified indicated that the screening program tended to detect glaucoma with less functional damage than the cases diagnosed conventionally, although the difference was not statistically significant, probably due to the low number of cases detected.

\section{Costs}

The individual cost of each activity is shown in Table 4. Costs of the primary care visit, ophthalmic visit at PPC, ophthalmic visit with testing, glaucoma screening, and glaucoma consultation were 15, 18, 52, 50, and $126 €$, respectively (Table 5). The cost of screening could be reduced from 50 to $38 €$ per

Table 4 Estimated individual costs

\begin{tabular}{|c|c|c|}
\hline Type of exam/location & Activity & Cost $(€)$ \\
\hline \multirow[t]{3}{*}{ Primary care center } & Admission/reception & 3.57 \\
\hline & Primary care visit & 10.18 \\
\hline & Structural cost & 1.96 \\
\hline Ophthalmology at primary & Admission/reception & 3.57 \\
\hline \multirow[t]{3}{*}{ care center } & Optometry visit & 5.43 \\
\hline & $\begin{array}{l}\text { Ophthalmology visit } \\
\text { (including material) }\end{array}$ & 6.23 \\
\hline & Structural cost & 1.96 \\
\hline \multirow[t]{3}{*}{$\begin{array}{l}\text { Glaucoma screening at } \\
\text { primary care center }\end{array}$} & $\begin{array}{l}\text { Examination } \\
\text { (technician and nurse) }\end{array}$ & 31.37 \\
\hline & Instruments & 10.69 \\
\hline & Training subject information & 8.54 \\
\hline \multirow[t]{4}{*}{ Glaucoma visit at hospital } & $\begin{array}{l}\text { Glaucoma consultation } \\
\text { (includes infrastructure }^{\mathrm{b}}=20 \% \text { ) }\end{array}$ & 55.41 \\
\hline & Fundus photograph & 37.44 \\
\hline & Visual field & 15.94 \\
\hline & Pachymetry & 17.74 \\
\hline
\end{tabular}

Notes: ${ }^{\mathrm{T}}$ This cost was calculated by optimizing the use of instruments and staff for a larger scale screening program. ${ }^{6}$ Data obtained from previous costs calculations. ${ }^{13,14}$
Table 5 Cost of glaucoma screening and conventional detection

\begin{tabular}{|c|c|c|c|}
\hline Variable & $\begin{array}{l}\text { Screening } \\
\text { in selected } \\
\text { sample }\end{array}$ & $\begin{array}{l}\text { Estimated } \\
\text { screening } \\
\text { in I million }\end{array}$ & $\begin{array}{l}\text { Conventional } \\
\text { detection } \\
\text { in population }\end{array}$ \\
\hline \multicolumn{4}{|c|}{ Sample/population } \\
\hline Subjects & $\mathrm{I}, 563$ & $1,000,000$ & 46,838 \\
\hline \multicolumn{4}{|c|}{ Cases examined } \\
\hline Subjects & 414 & 502,305 & 932 \\
\hline \multicolumn{4}{|c|}{ Primary care visits } \\
\hline Subjects & & 130,052 & 932 \\
\hline Cost/visit & & & 15.70 \\
\hline Total cost & & & $14,632.4$ \\
\hline \multicolumn{4}{|c|}{ Ophthalmic visit at primary care } \\
\hline Subjects & & & 677 \\
\hline Cost/visit & & & 18.69 \\
\hline Total cost & & & $12,653.13$ \\
\hline \multicolumn{4}{|c|}{ Ophthalmic visit at primary care with tests } \\
\hline \multicolumn{4}{|c|}{ (visual field + optic disc photograph) } \\
\hline Subjects & & & 165 \\
\hline Cost/visit & & & 52.37 \\
\hline Total cost & & & $8,641.05$ \\
\hline \multicolumn{4}{|c|}{ Screening program visits at primary care centre with tests (HRT, GDx) } \\
\hline Subjects & 414 & 130,052 & \\
\hline Cost/visit & 50.60 & 38.7 & \\
\hline Total cost & $20,946.90$ & $5,036,949.4$ & \\
\hline \multicolumn{4}{|c|}{ Glaucoma consultations at hospital with tests } \\
\hline \multicolumn{4}{|c|}{ (visual field + optic disc photograph + gonioscopy) } \\
\hline Subjects & 24 & 7,539 & 45 \\
\hline Cost/visit & 126.53 & 126,5 & 126.53 \\
\hline Total cost & $3,036.72$ & $954,022.9$ & $5,693.85$ \\
\hline Total cost & $23,983.62$ & $5,990,972.3$ & $4 I, 620.43$ \\
\hline
\end{tabular}

Abbreviations: GDx, nerve fiber analyzer; HRT, Heidelberg retina tomograph.

patient screened if applied to a population of 1 million by implementing a full-time screening program. This reduction is possible if the screening program is fully functional throughout the year and the costs of health professionals and infrastructure, but particularly those of the devices, can be distributed over a far greater number of cases evaluated.

The cost per case detected (Table 6) was similar for conventional detection $(1,435 €)$ and the screening program $(1,410 €)$. Sensitivity analysis revealed low to moderate modifications of the costs of the screening program. Costs would not have varied significantly if a mean of the detection rate calculated by other studies $(4.9 \%)^{8,9,27}$ using the same imaging devices was used to calculate cost per case detected. For the detection rate of $4.9 \%$, the cost per case detected by screening would have been $1,238 €$. Additionally, in the hypothetical setting of a fully implemented screening program directed at all inhabitants at risk for glaucoma in a population of 1 million subjects, the cost per case detected would be $1,121 €$.

Sensitivity analysis revealed moderate modifications of the cost-effectiveness of the screening program. If detection 
Table 6 Detection rate and cost per case detected

\begin{tabular}{llll}
\hline Variable & $\begin{array}{l}\text { Screening with } \\
\text { imaging devices } \\
\text { (sample) }\end{array}$ & $\begin{array}{l}\text { Screening applied in the NHS } \\
\text { to I million subjects. Screening } \\
\text { examination cost of 38.7€/person }\end{array}$ & $\begin{array}{l}\text { Conventional } \\
\text { detection } \\
\text { (population) }\end{array}$ \\
\hline Population & & $1,000,000$ & 46,838 \\
Population $>40$ years & 1,563 & 502,305 & 23,527 \\
Subjects examined (A) & 414 & 130,052 & 932 \\
Glaucoma cases detected (B) & 17 & 5,340 & 29 \\
Glaucoma detection rate (B/A) & 4.1 & 4.1 & 3.1 \\
Total cost (C) & $23,983.6$ & $5,990,972.3^{\mathrm{a}}$ & 41,620 \\
Cost/case detected (C/B) & I,4l0.8 & $1,121.8$ & $1,435.1$ \\
\hline Notes:
\end{tabular}

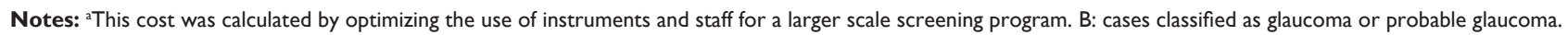
Abbreviation: NHS, National Health Survey.

rates from previous studies using HRT and GDx were used for calculations, the cost per case detected decreased to $1,238 €$. In a hypothetical setting where the screening program would be performed full time and directed at a population of 1 million subjects, the cost per case detected would be $1,121 €$.

\section{Discussion}

In Spain, as in many other developed countries, the health system fails to detect all glaucoma-affected patients. Imaging devices and a technology-based first assessment, as in the current study, could improve the number of cases detected while reducing screening costs. We used tonometry and 2 different imaging devices, avoiding functional tests, for 4 reasons. First, to shorten the testing time and to avoid the learning effect and inevitable repetition of functional tests, which are particularly relevant among inexperienced subjects. Second, tonometry and the 2 imaging devices are easy to transport to a remote screening center far from specialized clinics. Third, all 3 tests are easy to use and data acquisition is rapid. Finally, both imaging devices allow automatic classification using thoroughly evaluated algorithms with good sensitivity and specificity. ${ }^{9}{ }^{9}-19$ HRT sensitivity and specificity were $72.3 \%-91.5 \%$ and $84.0 \%-93.1 \%$ in a similar setting evaluated by Ohkubo et al. ${ }^{8}$ In a study with Reus et al, we observed that GDx and HRT outperformed European Ophthalmologists when classifying optic nerves. GDx-VCC nerve fiber indicator and the HRT best classifier correctly classified $93.2 \%$ and $89.9 \%$ of eyes, respectively. ${ }^{20}$ Toth et al observed that screening for glaucoma with GDx-VCC or HRT offers a sensitivity of $89.5 \%$ and $42 \%-92 \%$ and a specificity of $96.8 \%$ and $60 \%-82 \%$, respectively. ${ }^{9}$

The detection rate of $4.1 \%$ obtained with screening was similar to that found by Ohkubo et al (3.9\%) using only $\mathrm{HRT}^{8}$ and de Mul et $\mathrm{al}^{10}$ (4.6\%) using only GDx. Nevertheless, the detection rate was slightly lower than the $6.2 \%$ rate reported by Toth et al who used HRT and GDx in a smaller study. ${ }^{9}$ The detection rate with conventional detection was $3.1 \%, 1 \%$ lower than that obtained by active screening in this study. However, the cases identified by the screening program were characterized by a lesser degree of functional damage, including $88 \%$ of initial cases vs only $56 \%$ identified by conventional detection (Table 3). Quality of life has been shown to be significantly correlated with the degree of visual field damage, ${ }^{21}$ and initial field abnormalities have been associated empirically and by mathematical models to a reduced loss of the quality-adjusted life years (QALY) compared with more advanced cases. ${ }^{22}$

The non-acceptance to participate rate in the screening program was $36 \%$, a certainly high figure but comparable to that observed in other population-based studies and it is unlikely that it significantly influenced the results because the distribution in age groups of the sample is similar to that of the population (Table 2) with the only exception of the people with ages from 40 to 49 years (smaller percentage in the sample than in the population) who have relatively low prevalence of glaucoma. ${ }^{2}$

Cost calculation is complex and affected by multiple factors, varying significantly among different countries and settings. The estimated cost for a first visit to a glaucoma specialist including tests in the NHS in Spain was $126 €$ (\$137), while Schmier et al and Fremont et al estimated $\$ 582$ in Canada. ${ }^{23,24}$ Moreover, our study confirmed that the cost of screening is significantly affected by the scale and utilization of the service. The cost per case examined and the cost per case detected decreased from 50 to $38 €$ and from 1,410 to $1,211 €$, respectively, if screening was applied in a large population. The latter is slightly higher than the mean cost of $922 \$$ estimated by a meta-analysis on telemedicine glaucoma screening with photographs ${ }^{25}$ and lower than the cost of 2,561\$ per case computed by Blumberg et al using OCT. ${ }^{26}$ Also, costs would have not varied significantly if a mean 
of the detection rate calculated by other studies $(4.9 \%)^{8,9,27}$ using the same imaging devices was used to calculate cost per case detected.

The present study did not assess disease burden, but the effectiveness and utility of glaucoma screening certainly need further investigation. Information has been limited up to now and has been estimated mostly by the application of mathematical models. Vaahtotanta et al estimated an incremental cost of 32,602€ per year of avoided visual disability by screening and a cost of 9,023€ per QALY gained by screening. ${ }^{28}$ Peeters et a ${ }^{29}$ estimated an incremental cost-effectiveness ratio per year of vision saved of $1,707 €$ for tonometry in all patients and $4,444 €$ for tonometry in a high-risk group.

\section{Limitations}

The current study had limitations. Only the direct costs of screening or detection were considered but not the indirect (productivity) costs or intangible costs, such as qualityof-life deterioration, or cost of treatment. In addition, while performing a population-based study in a specific health care setting has the advantage of accurately reflecting the actual costs and effects in that particular setting, it also decreases the ability to extrapolate the results to other settings. Moreover, it is probable that conventional detection performed by ophthalmologists could identify certain other ophthalmic diseases with more sensitivity than glaucoma screening and this positive value could be subtracted from its costs. Additionally, the calculation of sensitivity, specificity, false positives, or false negatives was beyond the scope of this study and they cannot be calculated with the available data. Nevertheless, favorable values of detection rate, positive predictive values (53\% for screening and $21 \%$ for conventional detection), and estimated specificity $(56 \%-75 \%$ for screening) support the hypothesis that glaucoma screening with imaging devices improves the capabilities of conventional detection and could be cost-effective. The results also confirmed that the tested screening program would improve with a better specificity and, with this aim, present screening programs in our environment have been optimized through a better definition of target population (older age) and with the use of updated imaging devices and parameters.

\section{Conclusion}

In summary, tonometry and imaging devices integrated into a screening program and operated by nurses and optometrists identified new glaucoma cases with a detection rate of $4.1 \%$. The cost per case detected was $1,410 €$ and could be lowered to $1,121 €$ if applied to large populations. The incremental cost of screening for glaucoma in a population of 1 million inhabitants would be $5.1 €$ million but would also allow the detection of 4,715 new cases.

\section{Acknowledgment}

The study has been funded by the Fondo de Investigaciones Sanitarias of the Spanish Ministry of Health (FIS: 06/1167) and Allergan Spain.

\section{Disclosure}

The authors report no conflicts of interest in this work.

\section{References}

1. Burr JM, Mowatt G, Hernandez R, et al. The clinical effectiveness and cost-effectiveness of screening for open angle glaucoma: a systematic review and economic evaluation. Health Technol Assess. 2007:11(41): iii-iv, ix-x, 1-190.

2. Anton A, Andrada MT, Mujica V, Calle MA, Portela J, Mayo A. Prevalence of primary open-angle glaucoma in a Spanish population: the Segovia study. J Glaucoma. 2004;13(5):371-376.

3. Mowatt G, Burr JM, Cook JA, et al. Screening tests for detecting open-angle glaucoma: systematic review and meta-analysis. Invest Ophthalmol Vis Sci. 2008;49(12):5373-5385.

4. Kamdeu Fansi AA, Li G, Harasymowycz PJ. The validity of screening for open-angle glaucoma in high-risk populations with single-test screening mode frequency doubling technology perimetry (FDT). J Glaucoma. 20(3):167-171.

5. Wessels IF, Randhawa RS. Improving the sensitivity of the OKP visual field screening test with a blue stimulus on a dark background. Eye (Lond). 1996;10(Pt 5):620-625.

6. Pierre-Filho Pde T, Schimiti RB, de Vasconcellos JP, Costa VP. Sensitivity and specificity of frequency-doubling technology, tendency-oriented perimetry, SITA Standard and SITA Fast perimetry in perimetrically inexperienced individuals. Acta Ophthalmol Scand. 2006;84(3):345-350.

7. Deleon-Ortega JE, Arthur SN, McGwin G Jr, Xie A, Monheit BE, Girkin CA. Discrimination between glaucomatous and nonglaucomatous eyes using quantitative imaging devices and subjective optic nerve head assessment. Invest Ophthalmol Vis Sci. 2006;47(8): 3374-3380.

8. Ohkubo S, Takeda H, Higashide T, Sasaki T, Sugiyama K. A pilot study to detect glaucoma with confocal scanning laser ophthalmoscopy compared with nonmydriatic stereoscopic photography in a community health screening. J Glaucoma. 2007;16(6):531-538.

9. Toth M, Kothy P, Hollo G. Accuracy of scanning laser polarimetry, scanning laser tomography, and their combination in a glaucoma screening trial. J Glaucoma. 2008;17(8):639-646.

10. de Mul M, de Bont AA, Reus NJ, Lemij HG, Berg M. Improving the quality of eye care with tele-ophthalmology: shared-care glaucoma screening. J Telemed Telecare. 2004;10(6):331-336.

11. Blazquez F, Sebastian MA, Anton A. [Detection of glaucoma using SisGlaTel: acceptability and satisfaction among participants, and problems detected]. Arch Soc Esp Oftalmol. 2008;83(9):533-538. Spanish.

12. Hernandez R, Rabindranath K, Fraser C, Vale L, Blanco AA, Burr JM. Screening for open angle glaucoma: systematic review of costeffectiveness studies. J Glaucoma. 2008;17(3):159-168.

13. Morales E, Cots F, Sala M, et al. Hospital costs of nosocomial multidrug resistant Pseudomonas aeruginosa acquisition. BMC Health Serv Res. 2012;12:122. 
14. Benaiges D, Chillaron JJ, Carrera MJ, et al. Efficacy of treatment for hyperglycemic crisis in elderly diabetic patients in a day hospital. Clin Interv Aging. 2014;9:843-849.

15. Parikh RS, Parikh SR, Kumar RS, Prabakaran S, Babu JG, Thomas R. Diagnostic capability of scanning laser polarimetry with variable cornea compensator in Indian patients with early primary open-angle glaucoma. Ophthalmology. 2008;115(7):1167-1172. e1.

16. Toth M, Kothy P, Vargha P, Hollo G. Accuracy of combined GDx-VCC and matrix FDT in a glaucoma screening trial. J Glaucoma. 2007;16(5): $462-470$.

17. Vermeer KA, Reus NJ, Vos FM, Vossepoel AM, Lemij HG. Automated detection of wedge-shaped defects in polarimetric images of the retinal nerve fibre layer. Eye (Lond). 2006;20(7):776-784.

18. Moreno-Montanes J, Anton A, Garcia N, Mendiluce L, Ayala E, Sebastian A. Glaucoma probability score vs Moorfields classification in normal, ocular hypertensive, and glaucomatous eyes. Am JOphthalmol. 2008;145(2):360-368.

19. Sharma P, Sample PA, Zangwill LM, Schuman JS. Diagnostic tools for glaucoma detection and management. Surv Ophthalmol.2008;53(Suppl 1): S17-S32.

20. Reus NJ, Lemij HG, Garway-Heath DF, et al. Clinical assessment of stereoscopic optic disc photographs for glaucoma: the European Optic Disc Assessment Trial. Ophthalmology. 2010;117(4):717-723.

21. Orta AO, Ozturker ZK, Erkul SO, Bayraktar S, Yilmaz OF. The correlation between glaucomatous visual field loss and vision-related quality of life. J Glaucoma. 2015;24(5):e121-e127.

22. Rein DB, Wirth KE, Johnson CA, Lee PP. Estimating quality-adjusted life year losses associated with visual field deficits using methodological approaches. Ophthalmic Epidemiol. 2007;14(4):258-264.
23. Fremont AM, Lee PP, Mangione CM, et al. Patterns of care for openangle glaucoma in managed care. Arch Ophthalmol. 2003;121(6): 777-783.

24. Schmier JK, Covert DW, Robin AL. First-year treatment costs among new initiators of topical prostaglandin analog identified from November 2007 through April 2008. Curr Med Res Opin. 2011;26(12): 2769-2777.

25. Thomas SM, Jeyaraman MM, Hodge WG, Hutnik C, Costella J, Malvankar-Mehta MS. The effectiveness of teleglaucoma versus in-patient examination for glaucoma screening: a systematic review and meta-analysis. PLoS One. 2014;9(12):e113779.

26. Blumberg DM, Vaswani R, Nong E, Al-Aswad L, Cioffi GA. A comparative effectiveness analysis of visual field outcomes after projected glaucoma screening using SD-OCT in African American communities. Invest Ophthalmol Vis Sci. 2014;55(6):3491-3500.

27. Li G, Fansi AK, Harasymowycz P. Screening for glaucoma using GDx-VCC in a population with $\geq 1$ risk factors. Can J Ophthalmol. 2013;48(4):279-285.

28. Vaahtoranta-Lehtonen H, Tuulonen A, Aronen P, et al. Cost effectiveness and cost utility of an organized screening programme for glaucoma. Acta Ophthalmol Scand. 2007;85(5):508-518.

29. Peeters A, Schouten JS, Webers CA, Prins MH, Hendrikse F, Severens JL. Cost-effectiveness of early detection and treatment of ocular hypertension and primary open-angle glaucoma by the ophthalmologist. Eye (Lond). 2008;22(3):354-362.
Clinical Ophthalmology

\section{Publish your work in this journal}

Clinical Ophthalmology is an international, peer-reviewed journal covering all subspecialties within ophthalmology. Key topics include: Optometry; Visual science; Pharmacology and drug therapy in eye diseases; Basic Sciences; Primary and Secondary eye care; Patient Safety and Quality of Care Improvements. This journal is indexed on

\section{Dovepress}

PubMed Central and CAS, and is the official journal of The Society of Clinical Ophthalmology (SCO). The manuscript management system is completely online and includes a very quick and fair peer-review system, which is all easy to use. Visit http://www.dovepress.com/ testimonials.php to read real quotes from published authors. 